\title{
Higher quaternary ammonium salts with the sterically accessible exchange center: application for development of Selenate selective electrodes
}

\author{
Yu V Matveichuk* and Rakhman'ko EM \\ Belarusian State University, Republic of Belarus, Russia
}

\section{Article Info}

*Corresponding author:
Yu V Matveichuk
Belarusian State University
Leningradskaya str
14, Minsk, Republic of Belarus
220030
Russia
Email: Yu_Matveychuk@mail.ru

Received: October 31, 2017

Accepted: November 17, 2017

Published: November 23, 2017

Citation: Matveichuk YV, Rakhman'ko EM. Higher quaternary ammonium salts with the sterically accessible exchange center: application for development of Selenate selective electrodes. Madridge J Anal Sci Instrum. 2017; 2(1): 35-40.

doi: $10.18689 /$ mjai-1000108

Copyright: (c) 2017 The Author(s). This work is licensed under a Creative Commons Attribution 4.0 International License, which permits unrestricted use, distribution, and reproduction in any medium, provided the original work is properly cited.

Published by Madridge Publishers

\begin{abstract}
A new film selenate selective electrode has been developed, with the following membrane composition: (3,4,5-tris-dodecyloxybenzyl)tetraoxyethyl trimethyl ammonium chloride $(5 \% \mathrm{w} / \mathrm{w})$ as an electroactive component, (poly)vinyl chlorid $(33 \% \mathrm{w} / \mathrm{w})$ as a membrane matrix, 1-bromonaphtalene $(42 \% \mathrm{w} / \mathrm{w})$ as a plasticizer, (4-trifluoroacetyl) benzoic acid heptyl ester $(20 \% \mathrm{w} / \mathrm{w})$ as a neutral anion carrier. The electrode

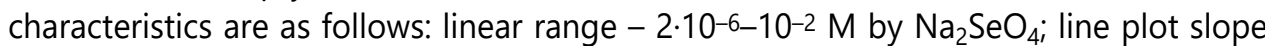

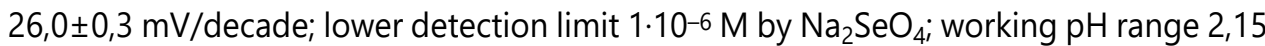
$-6,3$; potential drift $0,9 \mathrm{mV} / \mathrm{h}$; response time $15-90 \mathrm{~s}$; selectivity in presence of chloride, bromide, sulfate and other ions; lifetime up to 3 weeks. The electrode developed has been tested on model solutions using the standard addition method in the calibration plot variant, and bracketing technique.
\end{abstract}

Keywords: Selenate Selective Electrode; Sterically Accessible Quaternary Ammonium Salts; (4-trifluoroacetyl) Benzoic Acid Heptyl Ester.

\section{Introduction}

Selenium is a necessary trace element for plants, animals and humans. It occurs in nature mainly as selenides, selenites and selenates, and sometimes in the elementary state. The majority of selenides and selenium element itself have low toxicity due to their limited bioaccessibility, while selenites and selenates are toxic and act similarly to arsenic compounds, according to $[1,2]$. Selenium concentration and form of its occurrence in waters of various geochemical origin depends upon their mineralization, redox potential, $\mathrm{pH}$, iron content, proximity of oilfields etc.

For selenium determination, the following methods are currently in use: atomic adsorption spectroscopy, partition and ionic chromatography, stripping voltammetry, kinetic, fluorescent, photometric analysis, gas chromatography-mass spectrometry etc, as described in [1-7]. Despite the high sensitivity (approximately $10^{-6}-10^{-5} \mathrm{mg} / \mathrm{L}$ ), these methods often prove inefficient for direct selenium determination in complex objects. With background content of the analyte, the relative error can be as much as $50 \%$. Moreover, the above methods require complicated sample preparation, use of expensive equipment, specialized reagents and, sometimes, chemical pre-treatment such as reduction of $\mathrm{Se}(\mathrm{VI})$ into $\mathrm{Se}(\mathrm{IV})$. For instance, in Reference ${ }^{1}$ it is reported that, in mineral waters of Caucasian region, selenium (IV) and selenium (VI) are present in comparable amounts. To convert Se (VI) into Se (IV), authors propose reduction with concentrated hydrochloric acid under heating, followed by Se (IV) determination by extraction redox photometry. 
In this respect, ionometry, with its obvious objective advantages such as simple and quick sample preparation, wide range of concentrations determined and low equipment cost, looks very promising. An additional benefit is that both membranes and ion selective electrodes (ISE) themselves are easy to make and can be produced in any laboratory.

ISE developments for selenium determination are few and limited only to selenite ions, as mentioned in [8-10]. No information on selenate selective electrodes, either coated wire, film or solid contact type, or references thereof, has been found in the literature [11-18]. On the other hand, determination of selenium in selenate form is preferable in terms of greater stability of $\mathrm{Na}_{2} \mathrm{SeO}_{4}$ solutions compared to $\mathrm{Na}_{2} \mathrm{SeO}_{3}$. Long chain quaternary ammonium salts (QAS) proved themselves as promising materials for making anion selective ISEs. It has been believed that they uniformly have poor extraction capacity toward hydrophilic double charged anions (sulfate, selenate, carbonate etc.) due to strong hydration of these ions and steric hindrance by long hydrocarbon chains preventing simultaneous approach of two QAS cations to the double charged anion. The above is true, however, only for QAS cations having all four long-chain (no shorter than $C_{3}$ ) hydrocarbon substituents at the nitrogen atom. Therefore, it is interesting to test some new QAS, with improved steric access to the exchange center, against double charged anions.

It should be noted that the most spectacular successes in developing the ion-selective electrodes with nonstandard (anti-Hofmeister) selectivity were achieved with the aid of neutral anion carriers such as (4-trifluoroacetyl) benzoic acid heptyl ester (TFABAHE). That is why this compound was deemed necessary to use in the membrane of selenate selective electrodes.

Therefore, the goal of this work is to develop the new selenate selective electrode of high analytical performance based on long-chain QAS and TFABAHE. Several recently synthesized (as described in $[19,20]$ ) long-chain QAS with high steric accessibility of the exchange center such as (3,4,5-tris-dodecyloxybenzyl(oxyethyl) $)_{n}$ trimethyl ammonium chloride ((oxyethyl) $\left.)_{n} T M\right)$, where $\left.n=2-4\right)$; and 4-(3,4-bis-hexadecyloxyphenyl) butyl trimethyl ammonium bromide (BHPBTM) have been tested as anion exchangers for the first time.

\section{Experimental}

(Oxyethyl) $)_{n}$ TM; BHPBTM; trinonyl octadecyl ammonium iodide (TNODA), 3,4,5-tris-dodecyloxybenzyl tributyl ammonium chloride (TB), 3,4,5-tris-dodecyloxybenzyl triethyl ammonium chloride (TE) and 3,4,5-tris-dodecyloxybenzyl trimethyl ammonium chloride (TM) were used as electroactive membrane components; dibutyl phtalate (DBP, Sigma-Aldrich), 1-bromonaphtalene (1-BN) p.a., o-nitrophenyl decyl ether (o-NPDE), bis(2-ethylhexyl) decanedioate (BEHD), didecyl phthalate (DDP) as plasticizers; TFABAHE as the neutral anion carrier. Synthetic procedures for quaternary ammonium salts have been presented on Figure 1 and described in full detail in $[19,20]$. Structures of all new compounds have been confirmed by elemental analysis, NMR and IR spectra, which are also given in the same $[19,20]$. Solutions for ionometry were prepared from $\mathrm{K}_{2} \mathrm{SeO}_{4}$ p., $\mathrm{K}_{2} \mathrm{SO}_{4}$ p., $\mathrm{H}_{3} \mathrm{PO}_{4}$ p., $\mathrm{KCl}$ p.a., $\mathrm{NaBr}$ p. and $\mathrm{KNO}_{3}$ p.a.

ISE membranes contained the following components: (poly)vinyl chloride (PVC) 33\% w/w, the ion exchanger (QAS) $5 \% \mathrm{w} / \mathrm{w}$, the neutral anion carrier (TFABAHE) 20\% w/w; and the plasticizer $-42 \%$, with tetrahydrofurane (Fluka $A G$ ) as a solvent. They have been made according to a standard procedure described in [21]. All components were weighed precisely, dissolved in THF and mixed together. The obtained mixture was poured into the glass ring fixed on the glass plate and the solvent was allowed to evaporate overnight. Membrane disks (approximately 0.5-0.6 mm thick) were cut out from the master membrane and glued on the top of the PVC tubes with PVC-THF composition. and for the membrane composition.

The above proportions of membrane components have been selected on the basis of our previous works. In particular, in the [22] it has been shown that, for the membrane to be mechanically strong enough, the PVC content in the membrane should be no less than $33 \% \mathrm{w} / \mathrm{w}$. From preliminary experiments it has been established that the most stable performance of the ISE (potential reproducibility) is achieved at $5 \% \mathrm{w} / \mathrm{w}$ of QAS. The effect of the neutral anion carrier content on the analytical characteristics of ISE reversible to doubly charged inorganic ions, including selenate ions, was studied in Reference ${ }^{23}$, and it has been demonstrated that the optimum content of the neutral carrier is $20 \% \mathrm{w} / \mathrm{w}$. The rest of the membrane, i.e. $42 \% \mathrm{w} / \mathrm{w}$, is the plasticizer.

All newly made membranes have been soaked for 1-2 days in $1 \cdot 10^{-1} \mathrm{M}$ solutions of potassium selenate. The mixture of potassium selenate $\left(1 \cdot 10^{-2} \mathrm{M}\right)$ and potassium chloride (1.10-3 M) was used as an internal solution for all ISEs. In selenate solutions, $\mathrm{pH}$ was kept about $3.2 \pm 0.1$ using phosphoric acid solution, in order to remove the interference from carbonates and for better reproducibility. The same $\mathrm{pH}$ value was kept also in the interfering ion solutions while studying the selectivities of ISEs developed. ISE calibration was done by the double dilution method.

Activities of $\mathrm{SeO}_{4}{ }^{2-}$ ions in calibration solutions were calculated according to the Debye-Hückel theory (for $20^{\circ} \mathrm{C}$ ), as described in Reference 24 . Potentiometric selectivity coefficients were determined by the separate solutions method in the equal potential variant according to the formula given in [25].

$$
K_{i, j}^{\text {Pot }}=\frac{a_{i}}{a_{j}^{z_{i} / z_{j}}},
$$

where $a_{i}$ is the activity in the main ion solution at the $\mathrm{E}$ potential, $\mathrm{M} ; a_{j}$ is the activity in the interfering ion solution at the $E$ potential, $M_{i} z_{i}$ and $z_{j}$ are charges of the main and the interfering ions, respectively.

Sulfate, chloride, nitrate and bromide ions were selected as the interference, being the most frequently found in real objects. Slopes in the interfering ion solutions were, respectively, 24-25.5 mV/decade for sulfate, 50-51 mV/ 
decade for chloride, 51-52 mV/decade for bromide and 49-50 $\mathrm{mV} /$ decade for nitrate. Other characteristics were determined as recommended in [21].

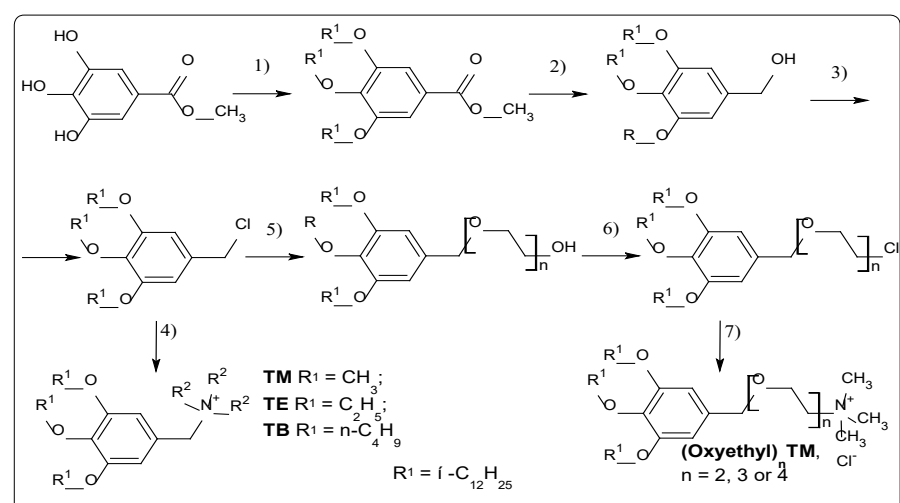

1) $\mathrm{R} 1 \mathrm{Br}, \mathrm{K}_{2} \mathrm{CO}_{3} /$ dimethyl formamide, 80-100i $\mathrm{N}$; 2) $\mathrm{LiAlH}_{4}$ / ether, reflux; 3) $\mathrm{SOCl} / \mathrm{CH}_{2} \mathrm{Cl}_{2}$, reflux; 4) $\mathrm{R}_{3}^{2} \mathrm{~N}^{3} / \mathrm{CH}_{3} \mathrm{CN}$, benzene; 5) $\mathrm{HO}_{2}\left(\mathrm{CH}_{2} \mathrm{CH}_{2} \mathrm{O}\right){ }_{\mathrm{n}} \mathrm{H}$, LiH / tetrahydrofuran, reflux; 6) $\mathrm{SOCl}_{2}^{2}$, $\mathrm{CH}_{2} \mathrm{Cl}_{2}$, reflux; 7) $\left(\mathrm{CH}_{3}\right)_{3} \mathrm{~N} / \mathrm{i}-\mathrm{PrOH}$,

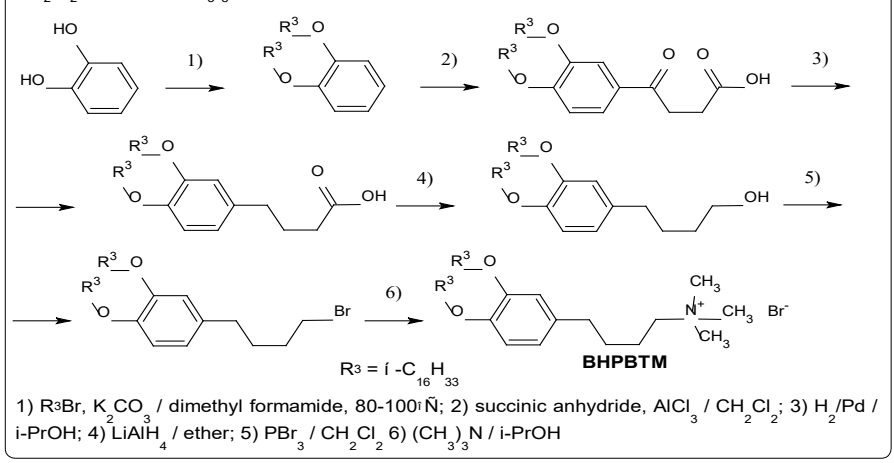

Figure 1. Synthesis of sterically accessible quaternary ammonium salts

The potential of the electrochemical cell was measured by the I-160.1MP (Republic of Belarus, Gomel Plant of Measuring Devices) ionometer at $20 \pm 10 \mathrm{C}$. The EVL-1M3.1 silver chloride electrode (Republic of Belarus, Gomel Plant of Measuring Devices) was used as a reference, and the ESL-43-07SR glass electrode (Republic of Belarus, Gomel Plant of Measuring Devices) - for $\mathrm{pH}$ measurement.

\section{Results and Discussion}

Selecting the working $\mathrm{pH}$ range. Figure 2 shows that the potential of the $\mathrm{SeO}_{4}{ }^{2-}$ selective electrode (based on (oxyethyl) ${ }_{2} \mathrm{TM}, \mathrm{TFABAHE}$ and $1-\mathrm{BN}$ ) is stable in the $\mathrm{pH}$ range from 2.25 to 6.3 and equals $-217 \pm 0.4 \mathrm{mV}\left(\right.$ at $C\left(\mathrm{~K}_{2} \mathrm{SeO}_{4}\right)=2.5 \cdot 10^{-3}$ M).

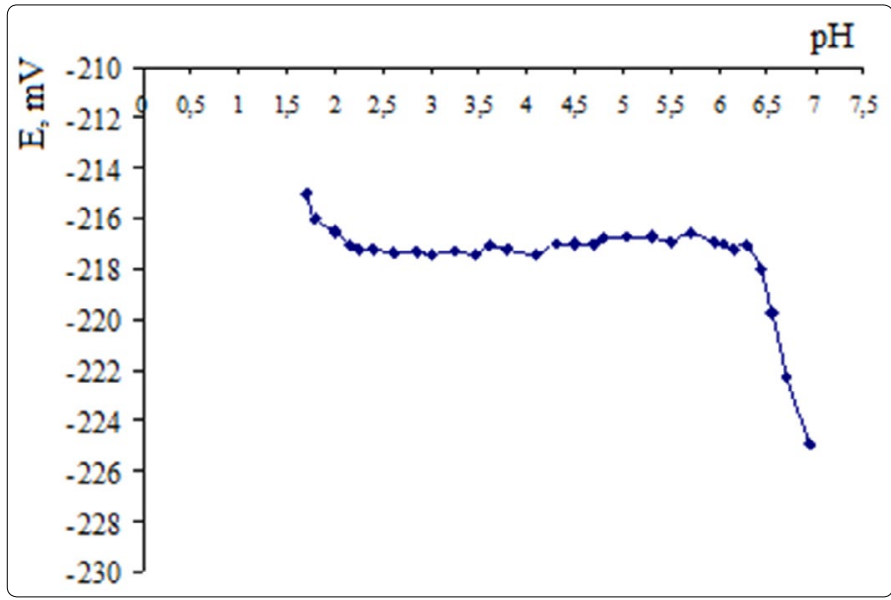

Figure 2. $\mathrm{pH}$ dependence of the selenate ISE potential
The ISE potential drops at $\mathrm{pH}>6.3$, due to interference of hydrogen carbonate and hydroxide ions. At $\mathrm{pH}$ below 2.25 selenate ions gradually convert to hydrogen selenate ions (since $\operatorname{lgK}_{\mathrm{a}}\left(\mathrm{HSeO}_{4}^{-}\right)=-1.8$, according to Reference ${ }^{24}$, about $20 \%$ of $\mathrm{Se}(\mathrm{VI})$ exist as $\mathrm{HSeO}_{4}{ }^{-}$at $\left.\mathrm{pH}=2.25\right)$.

As it was noted above, the $\mathrm{pH}$ value for potentiometric measurements has been maintained at $3.2 \pm 0.1$, excluding interference from hydrogen carbonate, sulfite, selenite, sulfide, hydrogen phosphate, fluoride etc. anions, as well as the majority of organic anions such as acetate, oxalate etc., due to their protonation. This makes unnecessary taking their interference into account, as it has been done in [8-10].

Lower detection limits and function slopes for selenate electrodes. Figures. 3, 4 show electrode functions of ISEs, Table 1 contains LDL values and electrode function slopes.

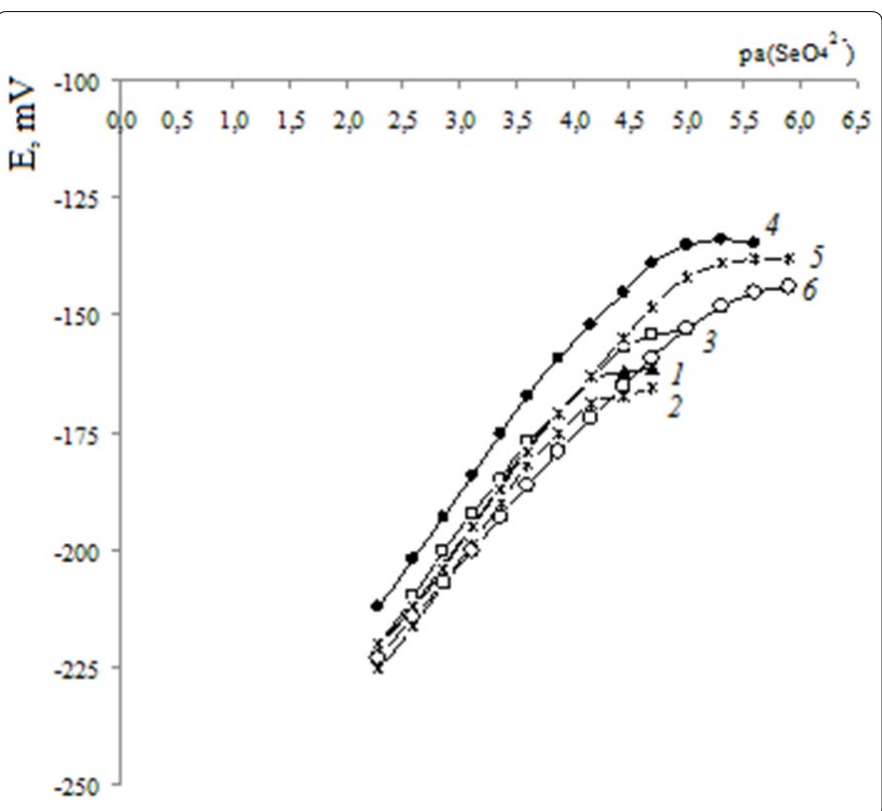

Figure 3. Electrode functions of selenate ISEs (no TFABAHE added; plasticized with DBP) based on: 1 - TNODA, 2 - TB, $3-\mathrm{TE}, 4-\mathrm{TM}, 5$ - BHPBTM, 6 - (oxyethyl) ${ }_{2}$ TM

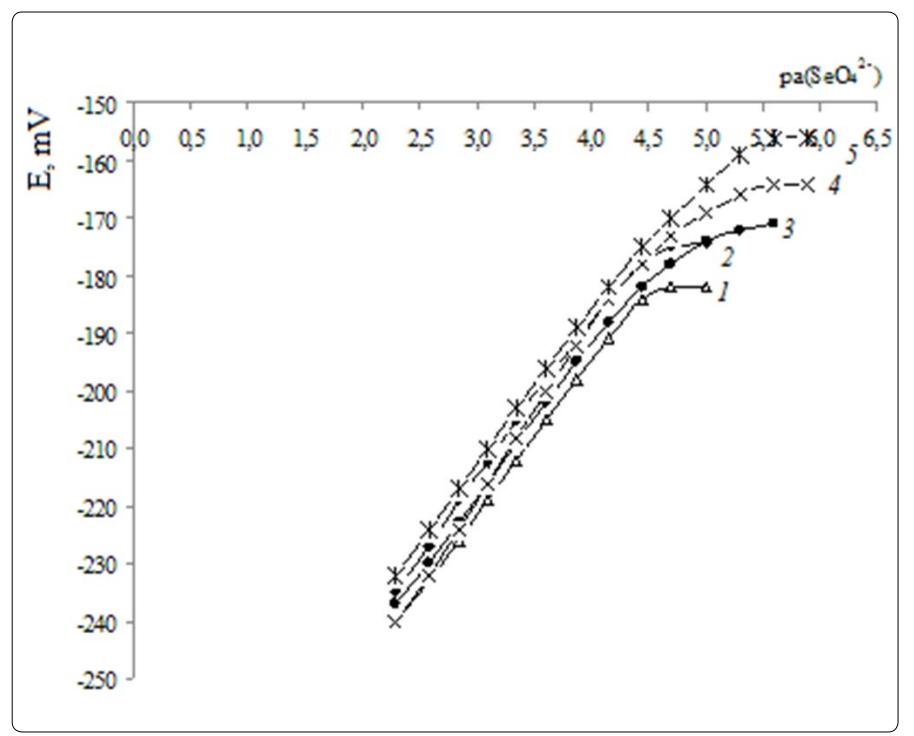

Figure 4. Electrode functions of selenate ISEs (with TFABAHE as a solvating additive; plasticized with DBP) based on: 1 - TNODA, 2 - TB, 3 - TE, 4 -TM, 5 - BHPBTM, 6 - (oxyethyl) ${ }_{2}$ TM 
It is evident (Table 1), that all ISEs developed have neartheoretical electrode function slopes and low LDL that decreases further with QAS exchange center steric access improvement, i.e. from TNODA to (oxyethyl) ${ }_{4}$ TM by 1.4 orders in absence of TFABAHE and by 0.9 orders in presence of it. Within the QAS series with improved steric access (from TM to (oxyethyl) ${ }_{4} T M$ ), LDL decreases by 0.8 and 0.3 orders, respectively.

Table 1. LDLs and electrode function slopes for selenate ISEs $(n=5)$

\begin{tabular}{|c|c|c|c|c|c|}
\hline $\begin{array}{l}\text { Without } \\
\text { TFABAHE }\end{array}$ & $\begin{array}{c}\text { Slope, } \mathrm{mV} / \\
\text { decade }\end{array}$ & LDL, M & With TFABAHE & $\begin{array}{c}\text { Slope, } \mathrm{mV} / \\
\text { decade }\end{array}$ & LDL, M \\
\hline TNODA & $31.2 \pm 0.3$ & $6.6 \cdot 10^{-5}$ & - & - & - \\
\hline TB & $31.0 \pm 0.4$ & $6.3 \cdot 10^{-5}$ & TB & $26.3 \pm 0.4$ & $3.2 \cdot 10^{-5}$ \\
\hline TE & $29.0 \pm 0.3$ & $2.4 \cdot 10-5$ & TE & $29.6 \pm 0.3$ & $2.2 \cdot 10^{-5}$ \\
\hline TM & $29.1 \pm 0.3$ & $1.8 \cdot 10^{-5}$ & TM & $25.8 \pm 0.6$ & $7.9 \cdot 10^{-6}$ \\
\hline BHPBTM & $29.6 \pm 0.3$ & $7.9 \cdot 10^{-6}$ & BHPBTM & $27.4 \pm 0.5$ & $5.6 \cdot 10^{-6}$ \\
\hline$(\text { oxyethyl) })_{2} \mathrm{TM}$ & $25.4 \pm 0.3$ & $3.2 \cdot 10^{-6}$ & (oxyethyl) ${ }_{2} \mathrm{TM}$ & $25.2 \pm 0.5$ & $4.0 \cdot 10^{-6}$ \\
\hline$\left(\right.$ oxyethyl) ${ }_{3} \mathrm{TM}$ & $25.5 \pm 0.4$ & $3.0 \cdot 10^{-6}$ & (oxyethyl) $)_{3} \mathrm{TM}$ & $25.8 \pm 0.2$ & $3.0 \cdot 10^{-6}$ \\
\hline$(\text { oxyethyl })_{4} \mathrm{TM}$ & $25.7 \pm 0.2$ & $2.8 \cdot 10^{-6}$ & (oxyethyl) ${ }_{4} \mathrm{TM}$ & $25.8 \pm 0.3$ & $1.6^{6} \cdot 10^{-6}$ \\
\hline
\end{tabular}

Selectivities of selenate ISEs. Table 2 contains $\lg K^{P o t}\left(\mathrm{SeO}_{4}{ }^{2-}\right.$, j) values for all selenate selective electrodes plasticized with DBP. The results show that the effect of exchange center steric accessibility increases from hydrophilic to hydrophobic anions: while switching from TNODA to (oxyethyl) ${ }_{4}$ TM brings down $\lg K^{\text {Pot }}\left(\mathrm{SeO}_{4}{ }^{2-}, \mathrm{SO}_{4}{ }^{2-}\right)$ only by 0.8 orders, the same change decreases $\lg K$ Pot $\left(\mathrm{SeO}_{4}{ }^{2-}, \mathrm{NO}_{3}{ }^{-}\right)$by as much as 5.5 orders.

Introducing TFABAHE into membranes improves selectivity dramatically. For instance, chloride and bromide ions show no interference with selenate. Somewhat unexpected is the fact that some selectivity is observed in presence of structurally similar sulfate ions; one of the possible explanations being greater polarity of $\mathrm{Se}-\mathrm{O}$ bond as compared to $\mathrm{S}-\mathrm{O}$ bond. It should be noted that introduction of TFABAHE into selenate ISEs produces greater selectivity improvement than for QAS-based sulfate ISEs as described in [26]. TFABAHE content in selenate ISE membranes was in all cases $20 \% \mathrm{w} / \mathrm{w}$, because it has been shown in Reference 27 that, to achieve high selectivity toward hydrophilic anions, it is necessary to use the neutral anion carrier in large excess to QAS.

For all ISEs, transition from (oxyethyl) 2 TM to (oxyethyl) ${ }_{4} \mathrm{TM}$ the net change of $\lg K$ Pot is about 0.1-0.4 orders.

Table 2. $\lg K$ Pot $\left(\mathrm{SeO}_{4}{ }^{2-}, \mathrm{j}\right)$ values for selenate ISEs

\begin{tabular}{|c|c|c|c|c|}
\hline \multirow{2}{*}{ Without TFABAHE } & \multicolumn{4}{|c|}{$\mathrm{Ig} \mathrm{Kot}^{\mathrm{Pot}}\left(\mathrm{SeO}_{4}{ }^{2-}, \mathrm{j}\right), \mathrm{n}=5$} \\
\cline { 2 - 5 } & $\mathrm{SO}_{4}{ }^{2-}$ & $\mathrm{Cl}^{-}$ & $\mathrm{Br}^{-}$ & $\mathrm{NO}_{3}{ }^{-}$ \\
\hline TNODA & $0.8 \pm 0.1$ & $3.5 \pm 0.3$ & $6.0 \pm 0.4$ & $7.2 \pm 0.5$ \\
\hline $\mathrm{TB}$ & $0.8 \pm 0.1$ & $3.5 \pm 0.3$ & $5.8 \pm 0.3$ & $7.0 \pm 0.4$ \\
\hline $\mathrm{TE}$ & $0.6 \pm 0.1$ & $2.8 \pm 0.2$ & $4.7 \pm 0.3$ & $5.7 \pm 0.3$ \\
\hline $\mathrm{TM}$ & $0.5 \pm 0.1$ & $1.9 \pm 0.1$ & $3.5 \pm 0.3$ & $3.8 \pm 0.3$ \\
\hline BHPBTM & $0.30 \pm 0.05$ & $1.2 \pm 0.1$ & $2.5 \pm 0.3$ & $2.6 \pm 0.2$ \\
\hline (oxyethyl) $_{2} \mathrm{TM}$ & $0.10 \pm 0.05$ & $0.6 \pm 0.1$ & $1.7 \pm 0.2$ & $1.9 \pm 0.2$ \\
\hline (oxyethyl) $_{3} \mathrm{TM}$ & $0.10 \pm 0.05$ & $0.6 \pm 0.1$ & $1.7 \pm 0.2$ & $1.8 \pm 0.2$ \\
\hline (oxyethyl) $_{4} \mathrm{TM}$ & 0.0 & $0.4 \pm 0.1$ & $1.55 \pm 0.1$ & $1.7 \pm 0.2$ \\
\hline With TFABAHE & $\mathrm{SO}_{4}{ }^{2-}$ & $\mathrm{Cl}-$ & $\mathrm{Br}$ & $\mathrm{NO}{ }_{3}^{-}$ \\
\hline $\mathrm{TB}$ & 0.0 & $-0.9 \pm 0.1$ & $-0.5 \pm 0.1$ & $1.8 \pm 0.2$ \\
\hline $\mathrm{TE}$ & $-0.20 \pm 0.05$ & $-0.9 \pm 0.1$ & $-0.7 \pm 0.1$ & $1.3 \pm 0.2$ \\
\hline $\mathrm{TM}$ & $-0.4 \pm 0.1$ & $-1.2 \pm 0.1$ & $-1.1 \pm 0.2$ & $0.4 \pm 0.1$ \\
\hline BHPBTM & $-0.6 \pm 0.1$ & $-1.6 \pm 0.1$ & $-1.4 \pm 0.2$ & $-0.10 \pm 0.05$ \\
\hline (oxyethyl) $_{2} \mathrm{TM}$ & $-0.7 \pm 0.1$ & $-2.0 \pm 0.2$ & $-1.8 \pm 0.2$ & $-0.4 \pm 0.1$ \\
\hline (oxyethyl) ${ }_{3} \mathrm{TM}$ & $-0.7 \pm 0.1$ & $-2.4 \pm 0.2$ & $-1.8 \pm 0.2$ & $-0.4 \pm 0.1$ \\
\hline (oxyethyl) ${ }_{4} \mathrm{TM}$ & $-0.7 \pm 0.1$ & $-2.4 \pm 0.2$ & $-1.9 \pm 0.2$ & $-0.45 \pm 0.05$ \\
\hline
\end{tabular}

The effect of plasticizer nature upon LDLs, selectivity and function slope. Figure 5 shows electrode functions for selenate ISEs with such plasticizers as 1-BN, BEHD and o-NPDE; LDL values, slopes and $\lg K^{\operatorname{Pot}}\left(\mathrm{SeO}_{4}{ }^{2-}, \mathrm{j}\right)$ are given in the Table 3.

Table 3. Characteristics of selenate ISEs with various plasticizers

\begin{tabular}{|c|c|c|c|c|c|c|}
\hline \multirow[b]{2}{*}{ Plasticizers } & \multirow{2}{*}{$\begin{array}{c}\text { Slope, } \mathrm{mV} / \\
\text { decade }\end{array}$} & \multirow[b]{2}{*}{ LDL, M } & \multicolumn{4}{|c|}{$\lg K^{\operatorname{Pot}}\left(\mathrm{SeO}_{4}{ }^{2-}, j\right), \mathrm{n}=5$} \\
\hline & & & $\mathrm{SO}_{4}^{2-}$ & $\mathrm{Cl}^{-}$ & $\mathrm{Br}^{-}$ & $\mathrm{NO}_{3}^{-}$ \\
\hline$o-\mathrm{NPDE}$ & $25.0 \pm 0.4$ & $5.8 \cdot 10^{-6}$ & $-0.5 \pm 0.1$ & $-1.7 \pm 0.1$ & $-1.5 \pm 0.1$ & $0.00 \pm 0.05$ \\
\hline BEHDa & $26.0 \pm 0.4$ & $5.0 \cdot 10^{-6}$ & $-0.7 \pm 0.1$ & $-1.9 \pm 0.1$ & $-1.7 \pm 0.1$ & $-0.20 \pm 0.05$ \\
\hline $\mathrm{DBPa}$ & $25.2 \pm 0.5$ & $4.0 \cdot 10^{-6}$ & $-0.7 \pm 0.1$ & $-2.0 \pm 0.2$ & $-1.8 \pm 0.2$ & $-0.3 \pm 0.1$ \\
\hline DDPa & $25.9 \pm 0.3$ & $3.2 \cdot 10^{-6}$ & $-0.75 \pm 0.10$ & $-2.1 \pm 0.1$ & $-1.8 \pm 0.3$ & $-0.4 \pm 0.1$ \\
\hline 1-BNa & $25.6 \pm 0.4$ & $1.8 \cdot 10^{-6}$ & $-0.9 \pm 0.1$ & $-2.3 \pm 0.1$ & $-2.1 \pm 0.1$ & $-0.5 \pm 0.1$ \\
\hline $1-\mathrm{BN} b$ & $25,3 \pm 0,5$ & $3.5 \cdot 10^{-6}$ & $-0.7 \pm 0.1$ & $-1.7 \pm 0.1$ & $-1.5 \pm 0.1$ & $0.10 \pm 0.05$ \\
\hline $1-\mathrm{BNC}$ & $26,0 \pm 0,3$ & $1.0 \cdot 10^{-6}$ & $-1.0 \pm 0.1$ & $-2.5 \pm 0.2$ & $-2.3 \pm 0.2$ & $-0.9 \pm 0.1$ \\
\hline
\end{tabular}

a ISE based on (oxyethyl) 2 TM. bISE based on TM. c ISE based on (oxyethyl) ${ }_{4}$ TM.

It is obvious from Table 3 that in the following series of plasticizers o-NPDE-BEHD $\approx$ DBP-DDF-1-BN, LDLs decrease by 0.5 orders (for (oxyethyl) 2 TM /TFABAHE based ISEs), while $\lg K^{\text {Pot }}\left(\mathrm{SeO}_{4}{ }^{2-}, \mathrm{j}\right)$ - by 0.6 orders for $\mathrm{Br}^{-}$, by 0.5 orders for $\mathrm{NO}_{3}{ }^{-}$, by 0.6 orders for $\mathrm{Cl}^{-}$, and by 0.4 orders for $\mathrm{SO}_{4}{ }^{2-}$, with neartheoretical slopes for all the ISEs studied.

A series of ISEs has been made using QASes with the enhanced stericaccess to the exchangecenter ((oxyethyl) ${ }_{2}$ TMand (oxyethyl) $\left.)_{4} T M\right)$, TFABAHE additive and 1-BN as a plasticizer. As shown in Table 4, increasing the spacer length between the aromatic ring and nitrogen atom (from TM, with no oxyethyl groups, to (oxyethyl) ${ }_{4} \mathrm{TM}$, with the longest chain) reduces $\left.\lg \mathrm{KPot}^{\mathrm{PeO}} \mathrm{Se}_{4}{ }^{2-}, \mathrm{j}\right)$ by 1.0 orders for $\mathrm{NO}_{3}{ }^{-}$, by 0.8 orders for $\mathrm{Br}^{-}$, by 0.8 orders for $\mathrm{Cl}^{-}$, by 0.3 orders for $\mathrm{SO}_{4}{ }^{2-}$.

The effects of the exchange center steric accessibility on the selenate ISE selectivity can be qualitatively interpreted in terms of the corresponding change of ion association constants for ions being exchanged: in the model where QAS exists in the form of ion triples with double charged anions and no associates of greater complexity are formed, the ion association constant $k_{a s}$ is described by Eigen-Denison-Ramsey-Fuoss equation [28].

$$
\lg k_{\text {as }}=-2,6+243 \cdot \frac{\left|\mathrm{z}_{\mathrm{a}} \cdot \mathrm{z}_{\mathrm{K}}\right|}{\varepsilon \cdot a}+3 \cdot \lg a,
$$

Where are charges of the anion and QAS cation being associated; $\varepsilon$ is the dielectric constant of the solvent; $a$ is the closest approach parameter for cations and anions being associated, $\AA$.

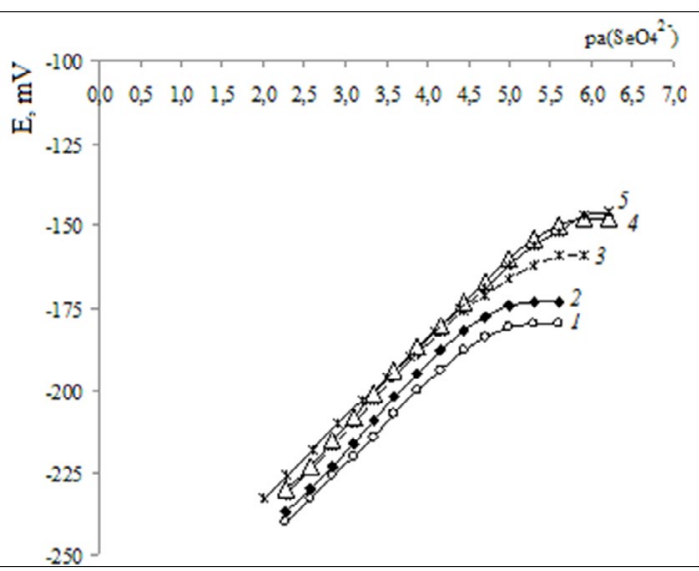

Figure 5. Electrode functions of selenate ISEs with TFABAHE as a neutral anion carrier and various plasticizers: 1 - TM, BEHD, $2-\mathrm{TM}, \mathrm{O}-\mathrm{NPDE}, 3$

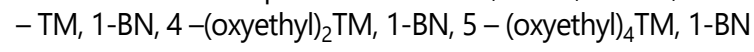


According to [28], in close ion pairs, where no solvent molecules are present between the associated ions, for QAS cations and anions $a$ parameter is about 4-7 A. Hence, with solvents with low or medium dielectric constant, such as DBP $(\varepsilon=6.4), \operatorname{DDP}(\varepsilon=4.4), \operatorname{BEHD}(\varepsilon=6)$ or 1 -BN $(\varepsilon=5)$ [24], the second member of Eigen-Denison-Ramsey-Fuoss equation makes the main contribution in $k_{\text {as }}$ value.

The $a$ parameter is, at least in the first approximation, an additive function of the anion and cation radii. It seems obvious that the effect of QAS exchange center steric accessibility on association constants must depend upon the size of ions being associated. Clearly, the improvement of steric access should lead to greater ion association constant increase for smaller anions $\left(r\left(\mathrm{SeO}_{4}{ }^{2-}\right)=2,49 \AA, r\left(\mathrm{SO}_{4}{ }^{2-}\right)=2.58 \AA\right.$, according to [29]). When single charged anions are substituted for double charged ones, decreasing the closest approach parameter should considerably increase the first association constant of a double charged anion with QAS cation. The removal of steric hindrance for approach of the ion pair (such as $\left.\mathrm{QAS}^{+} \ldots \mathrm{SeO}_{4}{ }^{2-}\right)$ to the second QAS cation should be accompanied by increase of the second association constant as well.

This trend for selectivity improvement is retained also in presence of such neutral carrier as TFABAHE. It should be noted that introduction of the neutral carrier levels both selectivity improvement and LDL decrease effects, that can be explained by solvate formation between anions and TFABAHE diminishing the effect of exchanging ion size itself.

Potential drift, response time, life time. Figures 6 and 7 are show the time dependencies for the selenate ISE with optimized membrane composition by QAS, plasticizer and solvating additive. The potential drift has been observed for 1 hour.

It is evident that ISE potential establishes quickly, but with decreasing concentration (activity) the response time becomes longer, the reason being the decreased content of main ions in the near-electrode layer and stronger interference from other ions.

The life time for selenate ISEs is about 3 weeks in presence of TFABAHE and up to 9 weeks in its absence.

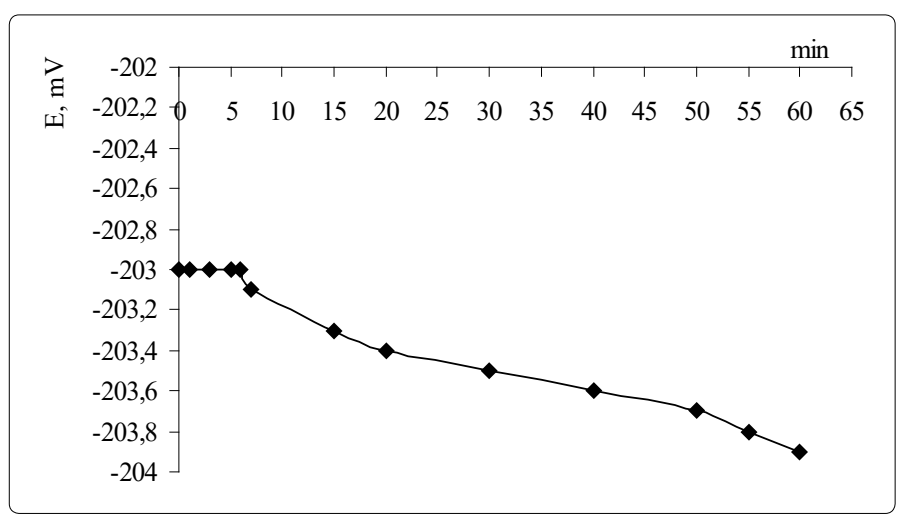

Figure 6. The potential drift for the ISE based on (oxyethyl) ${ }_{4} \mathrm{TM}$, TFABAHE and 1-BN

The potential drift for the ISE based on (oxyethyl) ${ }_{4} \mathrm{TM}_{\text {, }}$ TFABAHE and 1-BN is about $0.9 \mathrm{mV} / \mathrm{h}$, for $\mathrm{C}\left(\mathrm{SeO}_{4}{ }^{2-}\right)=4.5 \cdot 10^{-4} \mathrm{M}$.

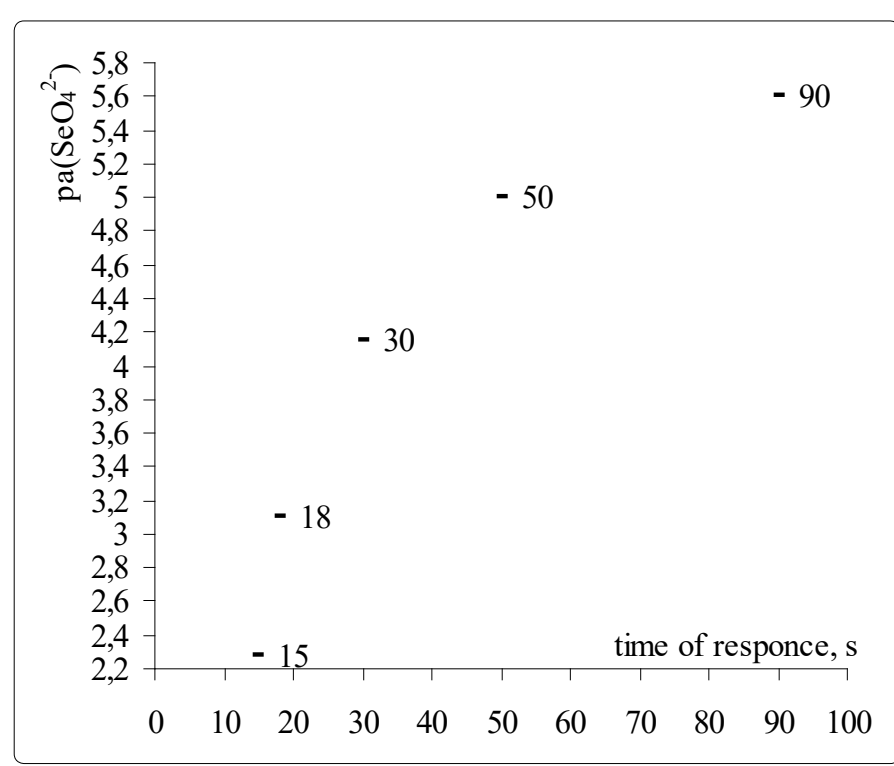

Figure 7. The response time for the ISE based on (oxyethyl) ${ }_{4} \mathrm{TM}$, TFABAHE and 1-BN

Determination of selenate ions in model solutions with the ISE based on (oxyethyl) ${ }_{4}$ TM, TFABAHE and 1-BN was performed by the calibration plot method and the limiting solutions method. In all solutions, $\mathrm{pH}$ has been maintained at $3.2 \pm 0.1$. In the limiting solutions method, two standard solutions were used, with selenate concentrations above $\left(C_{2}\right)$ and below $\left(C_{1}\right)$ their content in the target solution $\left(C_{x}\right)$. The calculations were done according to the formula:

$$
\lg _{\mathrm{X}}=\frac{\mathrm{E}_{\mathrm{X}}-\mathrm{E}_{1}}{\mathrm{E}_{1}-\mathrm{E}_{2}} \cdot\left(\lg \mathrm{C}_{2}-\lg \mathrm{C}_{1}\right)+\lg \mathrm{C}_{1}
$$

The results are presented in the Table 4.

Therefore, the limiting solutions method is preferable for determining selenate ions in model solutions as it provides more precision.

Table 4. Results of determination of selenate ions in model solutions

\begin{tabular}{|c|c|c|c|c|}
\hline $\begin{array}{c}\text { Introduced, mol } \\
\mathrm{L}^{-1}\end{array}$ & $\begin{array}{c}\text { Found, mol } \mathrm{L}^{-1} \\
\mathrm{SeO}_{4}^{2-} \\
\text { (calibrating plot) }\end{array}$ & $\mathrm{S}_{\mathrm{n}} \%$ & $\begin{array}{c}\text { Found, mol } \mathrm{L}^{-1} \mathrm{SeO}_{4}{ }^{2-} \\
\text { (the limiting solutions } \\
\text { method) }\end{array}$ & $\mathrm{S}_{\mathrm{n}} \%$ \\
\hline $1 \cdot 10^{-3}$ & $9.7 \cdot 10^{-4}$ & 8.4 & $9.8 \cdot 10^{-4}$ & 5.5 \\
\hline $1 \cdot 10^{-4}$ & $1.3 \cdot 10^{-4}$ & 9.1 & $9.9 \cdot 10^{-5}$ & 4.8 \\
\hline $5 \cdot 10^{-5}$ & $4.5 \cdot 10^{-5}$ & 9.6 & $5.2 \cdot 10^{-5}$ & 6.7 \\
\hline
\end{tabular}

\section{Conclusions}

It has been established that, of all ISEs studied, the

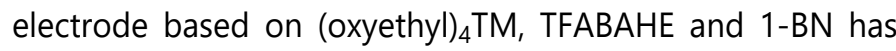
the best characteristics. Considerable LDL decrease and selenate selectivity improvement occurs in the following QAS series: $\quad$ TNODA-TB-TE-TM-BHPBTM-(oxyethyl) ${ }_{2}$ TM(oxyethyl) $)_{3} \mathrm{TM}$-(oxyethyl) ${ }_{4} \mathrm{TM}$. Therefore, the feasibility of «improved steric access» approach to designing ISEs for double charged anions is confirmed.

It has been found that, in the plasticizer series o-NPDE$B E H D \approx D B P-D D F-1-B N$ analytical characteristics improve considerably, that warrants recommendation of 1-bromonaphtalene as a plasticizer for selenate ISEs.

It has been shown that introducing TFABAHE as a neutral 
anion carrier improves selectivity of selenate ISEs considerably. The possibility of selenate determination in model solutions both by calibration plot method and limiting solutions method has been demonstrated.

\section{References}

1. Shlyapunova EV, Sergeev GM. Selective definition of the diverse forms of selenium in drinking waters. Vestnik N.I. Lobachevsky Nizhegor. Chemistry. 2009; 6: 96-100.

2. Conde JE, Sanz AM. Selenium concentrations in natural and environmental waters. Chem. Rev. 1997; 97(6): 1979-2004. doi: 10.1021/cr960100g

3. Korenovska M. Determination of arsenic, antimony, and selenium by FIHG-AAS in foods consumed in Slovakia. J. Food and Nutrition Research. 2006; 45(2): 84-88.

4. Zheng J, Shibata Y, Furuta N. Determination of selenoamino acids using two-dimensional ion-pair re-versed phase chromatography with on-line detection by inductively coupled plasma mass spectrometry. Talanta. 2003; 59(1): 27-36. doi: org/10.1016/S0039-9140(02)00460-5

5. Stozhko NYu, Morosanova El, Kolyadina LI, Fomina SV. Ceramic composite electrode for the determination of selenium (IV) by the method of inversion voltammetry. Rus. J. Anal. Chem. 2006; 61(2): 158-165. doi: $10.1134 / \mathrm{S} 1061934806020122$

6. Valencia MC, Nicolas EA, Capitan-Vallvey LF. Speciation of selenium (IV) in natural waters by solid phase spectrophotometry. Talanta. 1999; 49(4): 915-921. doi: 10.1016/s0039-9140(99)00088-0

7. Kapsimali DC, Zachariadis GA. Comparison of tetraethylborate and tetraphenylborate for selenite determination in human urine by gas chromatography mass spectrometry, after headspace solid phase microextraction. Talanta. 2010; 80(3):1311-1317. doi: 10.1016/j. talanta.2009.09.022

8. Ekmekçi G, Somer G. Preparation and properties of solid state selenite ion selective electrodes and their applications. Talanta. 1999; 49(1): 91-98. doi: 10.1016/S0039-9140(98)00350-6

9. Ibrahim $\mathrm{H}$, Issa $\mathrm{YM}$, Shehab Ola R. New selenite ion-selective electrodes based on 5,10,15,20-tetrakis-(4-methoxyphenyl)-21H,23H-porphyrinCo(II). J. Hazardous Materials. 2010; 181(1-3): 857-867. doi: 10.1016/j. jhazmat.2010.05.092

10. Ekmekçi G, Somer G. A new selenite selective membrane electrode and its application. Talanta. 1999; 49(1): 83-89. doi: 10.1016/S0039-9140(98)00353-1

11. Ganjali MR, Norouzi P, Faridbod F, Rezapour M, Pourjavid MR. One Decade of Research on Ion-Selective Electrodes in Iran (1996-2006). J. Iran. Chem. Soc. 2007; 4(1): 1-29.

12. Antonisse MMG, Reinhoudt DN. Potentiometric Anion Selective Sensors. Electroanalysis. 1999; 11(14): 1035-1048. doi: 10.1002/(sici)15214109(199910)11:14<1035:.:aid-elan1035>3.0.co;2-i

13. Antonisse MMG, Reinhoudt DN. Neutral Anion Receptors: Design and Application. Chem.Commun. 1998; 23(4): 443-447. doi: 10.1039/A707529D

14. Gupta VK. Potentiometric sensors for inorganic anions based on neutral carrier. Arab. J. Sci. Eng. 2010; 35: 7-25.
15. Umezawa Yo, Umezawa K, Bühlmann Ph, Nishimura Y. Potentiometric selectivity coefficients of ion-selective electrodes Part II. Inorganic anions (Technical Report). Pure Appl. Chem. 2002; 74(6): 923-994.

16. Koseoglu SS, Lai CZ, Ferguson C, Bühlmann Ph. Response Mechanism of Ion-Selective Electrodes Based on a Guanidine lonophore: An Apparently Two-Thirds Nernstian Response Slope. Electroanalysis. 2008; 20(3): 331339. doi: 10.1002/elan.200704066

17. Bühlmann Ph, Chen Li D. Ion-Selective Electrodes with lonophore-Doped Sensing Membranes, Supramolecular Chemistry: From Molecules to Nanomaterials. John Wiley \& Sons. 2012; 5: 2539-2579.

18. Bühlmann Ph, Pretsch E, Bakker E. Carrier-Based Ion-Selective Electrodes and Bulk Optodes. 2. Ionophores for Potentiometric and Optical Sensors. Chem. Rev. 1998; 98(4): 1593-1688. doi: 10.1021/cr970113+

19. Okaev EB, Stanishevsky LS. Synthesis of quaternary ammonium salts with increased steric availability of the cationic center, promising as electrode compounds. Chemical Technologies of Functional Materials: proceedings of the III rd International Russia-Kazakhstan Conference (Russian). Novosibirsk NSTU. 2017; 13-15.

20. Okaev EB. Synthesis of new highly lipophilic quaternary ammonium salts with regulated steric accessibility of the cationic center. Proceedings of the National Academy of Sciences of Belarus. Chemistry Series. 2005; 1: 53-57.

21. K. Kamman, Working with ionoselective electrodes (Russian). Moscow: Mir. 1980: p288.

22. Egorov VV, Nazarov VA, Okaev EB, Pavlova TE. A new sulfate selective electrode and its use in analysis. J. Anal. Chem. 2006; 61(4): 382-388. doi: $10.1134 /$ S1061934806040150.

23. Matveichuk Yu, Rakhman ko E, Akayeu Ya, Stanishevskii D. Ion selective electrodes based on long-chain quaternary ammonium salts with enhanced steric accessibility, and their application for determination of hydrophilic double charged inorganic anion. Chem. Pap. 2017. doi: 10.1007/s11696-017-0320-7

24. Dean J.A. Lange's handbook of chemistry. McGRAW-HILL, INC.1999: p1291.

25. Bakker E, Pretsch E, Bühlmann Ph. Selectivity of Potentiometric lon Sensors. Anal. Chem. 2000. 72(6): 1127-1133. doi: 10.1021/ac991146n

26. Matveychuk YuV, Okaev EB. New quaternary ammonium salts: application in ionometry Chemical Technologies of Functional Materials: proceedings of the III rd International Russia-Kazakhstan Conference (Russian). Novosibirsk NSTU. 2017; 20-23.

27. Lomako SV, Astapovich RI, Nozdrin-Plotnitskaya OV et.al. Sulfate-selective electrode and its application for sulfate determination in aqueous solutions. Anal. Chim. Acta. 2006; 562(2): 216-222. doi: 10.1016/j. aca.2006.01.047

28. Nazarov VA, Andronchik KA, Egorov VV, Matulis VE, Ivashkevich OA. Intramembrane complex formation study of ion selective electrode based on heptyl p-trifluoroacetylbenzoic ether. Electroanalysis. 2011. 23(5): 1058-1066. doi: 10.1002/elan.201000606

29. Jenkins HDB, Thakur KP. Reappraisal of thermochemical radii for complex ions. J. Chen. Education. 1979. 56(9): 576-577. doi: 10.1021/ed056p576 